\title{
Coupling of internal and external cooling of gas turbine blades
}

\author{
F. Ghezali ${ }^{1, a}$, A. Azzi ${ }^{1}$ And A. Bouzidane ${ }^{2}$ \\ 1 Laboratoire Aero Hydrodynamique navale, Faculté de Génie-Mécanique,Université des Sciences et de la Technologie Mohamed \\ Boudiaf d'Oran, USTMB d'Oran, BP 1505, El-Mnaouar, Algérie \\ 2 Univ Tiaret. Fac. Sciences Appliquées, BP 78 City/Province, Tiaret 14000, Algeria
}

Received 13 February 2013, Accepted 27 February 2014

\begin{abstract}
Showerhead cooling process which consists of internal convective cooling and external film cooling of a turbine blade is investigated using ANSYS-CFX software. The aim of the present investigation is to provide a better understanding of the fundamental nature of showerhead cooling using the three dimensional Reynolds averaged Navier Stokes analysis. A numerical model has been developed to study the effects of coupled internal and external cooling of the leading edge for a semi-elliptical body shape with the SST $k-\omega$ model. This model consists of all internal flow passages and cooling hole rows at the leading edge. The numerical results obtained are discussed and compared with experimental data available in the literature. The results show that the cooling efficiency increases with the increase of the blowing ratio and the Mach number, therefore, the overall efficiency for the steel becomes less important compared to the plexiglas which has a low thermal conductivity.
\end{abstract}

Key words: Film cooling / turbine blade / ANSYS-CFX / cooling efficiency / SST $k-\omega$ / thermal conductivity

\section{Introduction}

The development of a new generation of high performance aircraft turbine jet engines requires gas turbines to be operated at very high turbine rotor inlet gas temperatures. This needs the development of more innovative cooling techniques for the gas turbine blades. It is also important to reach this goal by using the minimal coolant blowing ratio. The cooling techniques available can be classed in two main categories: internal and external cooling methods. The internal cooling techniques use convective process to reduce the heat from the inside of the airfoil. The effectiveness of these processes is highly enhanced by the use of labyrinth passages, pin fins and impingements jets.

The external cooling techniques which are used for the highly thermal loaded blades reduce the heat flux going into external surfaces of the turbine vanes and blades. In this process a relatively cold air is injected from the interior to the exterior part to be cooled. Among many others, film cooling technique has been used for gas turbine blades for more than five decades [1-9]. However, the effectiveness of film cooling of gas turbine blades is very much dependent on the shape of the injection holes. The shapes of the hole, layout geometry, and injection angle,

\footnotetext{
${ }^{a}$ Corresponding author: faiza_ghezali@yahoo.fr
}

etc. are very critical deciding factors. The optimization of such techniques is realized by the choice of many geometrical parameters such as the stream wise and spanwise angle of holes inclination, the kind of holes: cylindrical, shaped or optimized form, the number of rows, the distance between successive rows and between holes in the same row, the spatial position of the rows from the stagnation line: near the leading edge, pressure or suction sides.

Many studies have been performed for the development of advanced film-cooling holes. Gao and Han [10] experimentally studied the effects of film-hole geometry and angle on turbine blade leading edge film cooling using the pressure sensitive paint technique. The results show that the shaped holes provide higher film cooling effectiveness than the cylindrical holes particularly at higher average blowing ratios and the radial angle holes give better effectiveness than the compound angle holes. Lee and Kim [11] studied the film-cooling performance of the novel shaped holes by comparison with that of fan-shaped holes; overall, with an increase in the blowing ratio, the novel shaped hole shows greatly improved film cooling effectiveness and lateral spreading of coolant. Elnady et al. [12] presented an experimental investigation performed to evaluate the employment of smooth expansion hole positioned at the leading edge of a gas turbine stator. Two expansion levels, $2 \mathrm{~d}$ and $4 \mathrm{~d}$ have been investigated in addition to the standard cylindrical hole at two inclination angles, 


\section{Nomenclature}

\begin{tabular}{|c|c|}
\hline$a$ & Sound velocity, $(\gamma R T)^{0.5}\left[\mathrm{~m} . \mathrm{s}^{-1}\right]$ \\
\hline$D$ & Leading edge cylinder diameter $[\mathrm{m}]$ \\
\hline$d$ & Diameter of the holes $[\mathrm{m}]$ \\
\hline$G$ & Blowing ratio, $G=\rho_{\mathrm{c}} u_{\mathrm{c}} / \rho_{\mathrm{g}} u_{\infty},[-]$ \\
\hline$h$ & Heat transfer coefficient $\left[\mathrm{W} \cdot \mathrm{m}^{-2} \cdot \mathrm{K}^{-1}\right]$ \\
\hline$k$ & Thermal conductivity $\left[\mathrm{W} \cdot \mathrm{m}^{-1} \cdot \mathrm{K}^{-1}\right]$ \\
\hline$L$ & Holes length $[\mathrm{m}]$ \\
\hline$M$ & Mach number, $M=u_{\mathrm{g}} / a[-]$ \\
\hline$p$ & Pressure $[\mathrm{Pa}]$ \\
\hline$P$ & Pitch spacing between holes in one row $[\mathrm{m}]$ \\
\hline$q_{\mathrm{f}}$ & Heat flux from outside part to solid, [W] \\
\hline$q_{\text {hole }}$ & $\begin{array}{l}\text { Heat flux from the solid to holes } \\
\text { passages, }[\mathrm{W}]\end{array}$ \\
\hline$q_{\text {plen }}$ & $\begin{array}{l}\text { Heat flux from the solid to plenum } \\
\text { chamber, }[\mathrm{W}]\end{array}$ \\
\hline$R e_{\mathrm{D}}$ & Reynolds number, $R e_{\mathrm{D}}=\rho u_{\mathrm{g}} D / \mu[-]$ \\
\hline$R$ & Rang of holes \\
\hline$S$ & $\begin{array}{l}\text { Surface distance from the stagnation point } \\
\text { of blunt body }[\mathrm{m}]\end{array}$ \\
\hline$t$ & Time $[s]$ \\
\hline$T$ & Temperature $[\mathrm{K}]$ \\
\hline$T_{\mathrm{m}}$ & Mean solid temperature \\
\hline$T_{\mathrm{w}, \mathrm{g}}$ & Wall adjacent temperature to hot gas $[\mathrm{K}]$ \\
\hline$T_{\mathrm{w}, \text { plen }}$ & $\begin{array}{l}\text { Wall adjacent temperature to } \\
\text { plenum side }[\mathrm{K}]\end{array}$ \\
\hline$T u$ & Free stream turbulence intensity [\%] \\
\hline$u$ & Velocity $\left[\mathrm{m} \cdot \mathrm{s}^{-1}\right]$ \\
\hline$u_{\infty}$ & Velocity of main flow $\left[\mathrm{m} \cdot \mathrm{s}^{-1}\right]$ \\
\hline \multicolumn{2}{|c|}{ Greek Symbols } \\
\hline$\alpha$ & Thermal diffusivity, $\alpha=k /\left(\rho c_{p}\right)\left[\mathrm{m}^{2} . \mathrm{s}^{-1}\right]$ \\
\hline$\beta$ & Spanwise inclination $\left[{ }^{\circ}\right]$ \\
\hline$\gamma$ & Exit location angles $\left[^{\circ}\right]$ \\
\hline$\eta$ & Film cooling effectiveness, $[-]$ \\
\hline$\varphi$ & Stream wise inclination $\left[{ }^{\circ}\right]$ \\
\hline$\Gamma$ & Isentropic exposant, $\kappa=c_{p} / c_{v}[-]$ \\
\hline$\mu$ & Dynamic viscosity $\left[\right.$ N.s.m $\left.{ }^{-2}\right]$ \\
\hline$\theta$ & Angle from the stagnation point $\left[^{\circ}\right]$ \\
\hline$\rho$ & Density $\left[\mathrm{kg} \cdot \mathrm{m}^{-3}\right]$ \\
\hline$\tau$ & Shear stress or sub-grid scale stress \\
\hline$\delta$ & Identity matrix or Kronecker \\
\hline \multicolumn{2}{|c|}{ Indices } \\
\hline c & Coolant air \\
\hline $\mathrm{f}$ & Main flow \\
\hline $\mathrm{g}$ & Hot gas \\
\hline$h$ & Injection hole \\
\hline aw & Adiabatic wall \\
\hline i & Hole entry conditions (cooling side) \\
\hline o & Hole exit conditions (hot gas side) \\
\hline plen & Plenum \\
\hline $\mathrm{w}$ & Wall \\
\hline
\end{tabular}

$90^{\circ}$ and $60^{\circ}$. The smooth expansion exit shows higher effectiveness compared with the standard cylindrical exit when supplied with the same coolant amount. Numerical studies on leading edge film cooling have been reported by Kim and Kim [13]. They examined the film cooling performance for the turbine blade leading edge region using five different cylindrical body models with various injection holes, which are a baseline cylindrical hole, two laidback (spanwise-diffused) holes, and two tear-drop shaped (spanwise- and treamwise-diffused) holes. They found that the laidback hole (Shape D) provides better film cooling performance than the other holes and the broader region of high effectiveness is formed with fairly uniform distribution. The blowing ratio which is defined as the ratio density-velocity between the injected cold air and the mainstream hot gas is also a very important parameter that affect directly the film cooling effectiveness [14]. Most previous published studies, both experimental and numerical ones, have been focused either on internal or external cooling techniques, and when examining those dealing with film cooling techniques they always advise the use of low blowing ratio. This is justified by the fact that at high blowing ratio the jet "lifts off" far from the solid wall and consequently the blade protection is decreased [15-19].

Recently, Yao et al. [20] have been conducted to understand the characteristics of a row of cylindrical holes with three geometries for the branched jet injection holes and four blowing ratios were considered. They found that, at increased blowing ratios, the branched jet injection design produces a clearer improvement in film effectiveness, especially when the exit of the branched jet injection holes is in line with or downstream of the primary film cooling holes. Researches from Swiss Federal Institute of Technology-Lausanne (EPFL) [4] focused on the effect of both external and internal cooling in the leading edge part of the airfoil. Two kinds of conditions are used: the so called experimental conditions with low conductivity material (plexiglas) and engine like conditions with steel as blade material. The parameter used for comparison purpose is the overall cooling effectiveness corresponding to a non-dimensional average material temperature. The main conclusions of these investigations are that high blowing injected ratio provides the best cooling performances and the material thermal conductivity is a critical parameter in such cooling techniques. In real engine like conditions, the internal convective cooling includes both the inside of the holes and the backside part of the blade which play a major role in the global resulting cooling of the blade. So, when increasing the blowing ratio, the cooling effectiveness added by the internal cooling is more important than that lost from the external film cooling due to the lift off of the jet. The present work is a continuation of the investigations performed by Falcoz et al. [5]. In this work, more global numerical computations are performed. Both fluid flow and heat transfer are considered and coupled with the conductive process into the blade material. In such conjugate heat transfer computation there is no need to use experimental thermal 


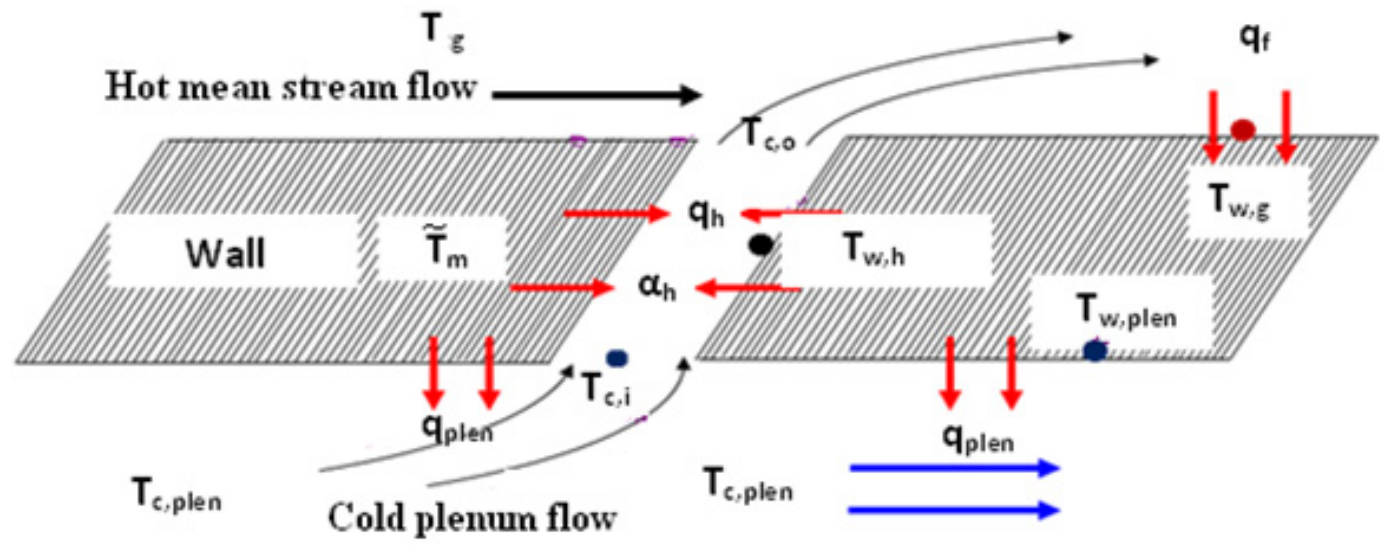

Fig. 1. Internal and external cooling processes.

distribution or empirical correlations and only inlet conditions are used. Such computations are expected to give more precise conclusions, which are free from approximations due to boundary conditions assumptions.

\section{Governing equations and simulation}

The computations are done by use of the very suited commercial code ANSYS CFX 12 which incorporates conjugate heat transfer capability. Figure 1 shows an internal and external cooling process configuration. In this configuration, the additional forced convective cooling occurring inside the holes represents a great potential for cooling the leading edge. Consequently the leading edge region of modern film cooled air foil is cooled down via three cooling mechanisms:

(a) the back side cooling occurring inside the core of the airfoil (also cooled the cold side) and generated by an internal cooling technique;

(b) the forced convective cooling inside the holes when the coolant passes through the holes. The back side and forced convective cooling are usually summarized as the internal convective cooling;

(c) and the film cooling which takes place on the external surface after the cooling fluid is ejected.

As described by Harasgama [9] and reported by Falcoz [4], the three dimensionless parameters can be defined:

- The overall cooling effectiveness:

$$
\varepsilon=\frac{T_{\mathrm{g}}-\tilde{T}_{\mathrm{m}}}{T_{\mathrm{g}}-T_{\mathrm{c}, \mathrm{i}}}
$$

- The film cooling effectiveness:

$$
\eta=\frac{T_{\mathrm{g}}-T_{\mathrm{aw}}}{T_{\mathrm{g}}-T_{\mathrm{c}, \mathrm{o}}}
$$

- The cooling effectiveness $(\Psi)$ defined as:

$$
\Psi=\frac{T_{\mathrm{c}, \mathrm{o}}-T_{\mathrm{c}, \mathrm{i}}}{\tilde{T}_{\mathrm{m}}-T_{\mathrm{c}, \mathrm{i}}}
$$

Table 1. Geometrical parameters describing the showerhead configuration [4].

\begin{tabular}{lcc}
\hline Number of rows & \multicolumn{2}{c}{4} \\
\hline Diameter ratio & $d / D$ & 0.033 \\
Exit location angles & $\gamma$ & $\pm 22.5^{\circ} / \pm 7.5^{\circ}$ \\
Length of holes & $L / d$ & 6 \\
Spanwise pitch & $P / d$ & 4 \\
Stream wise inclination & $\varphi$ & $90^{\circ}$ \\
Spanwise inclination & $\beta$ & $45^{\circ}$ \\
\hline
\end{tabular}

Where:

- $T_{\mathrm{g}}$ the temperature of the hot gas;

- $\tilde{T}_{\mathrm{m}}$ the average blade temperature;

- $T_{\mathrm{c}, \mathrm{i}}$ the air temperature at the hole inlet;

- $T_{\mathrm{c}, \mathrm{o}}$ the air temperature at the hole exit;

- $T_{\mathrm{aw}}$ the adiabatic wall temperature.

The test case is a blunt body with an elliptical leading edge profile with $21 \mathrm{~mm}$ diameter, equipped by four rows of cylindrical holes. The diameter is $d=0.7 \mathrm{~mm}$. The ratio between the length of the holes $L$ and the diameter is $L / d=6$. The spanwise injection angle is $\beta=45^{\circ}$ and the stream wise inclination angle is $\varphi=90^{\circ}$. Rows are distributed symmetrically with respect to the stagnation point. Table 1 shows the geometrical parameters describing the showerhead configuration. Overview of the test model and additional geometrical details are provided by Figure 2, and Table 1.

The computational domain is composed by one spanwise pitch corresponding to $2.8 \mathrm{~mm}$ (4d) and periodic conditions are prescribed. Figure 3 shows perspective views of the computational domain done with the ICEM.CFD mesh generator included with the CFX-12 software. A close view of the computational unstructured grid from $G=0.4$ is presented in Figure 4 which is composed by 99033 nodes and 149776 elements corresponding to the solid and fluid domain respectively. In order to improve the accuracy of the near wall treatment flattened prism elements are used close to the walls. Table 2 shows the materials properties of plexiglas.

According to the experimental approach parameters, the main stream hot velocity is computed and set 

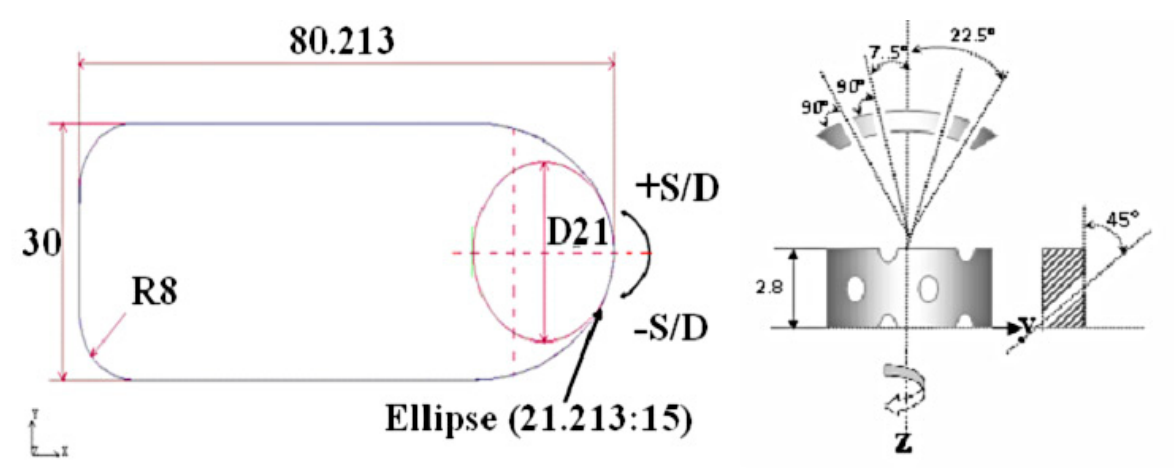

Fig. 2. Showerhead blunt body model, dimensions in mm.
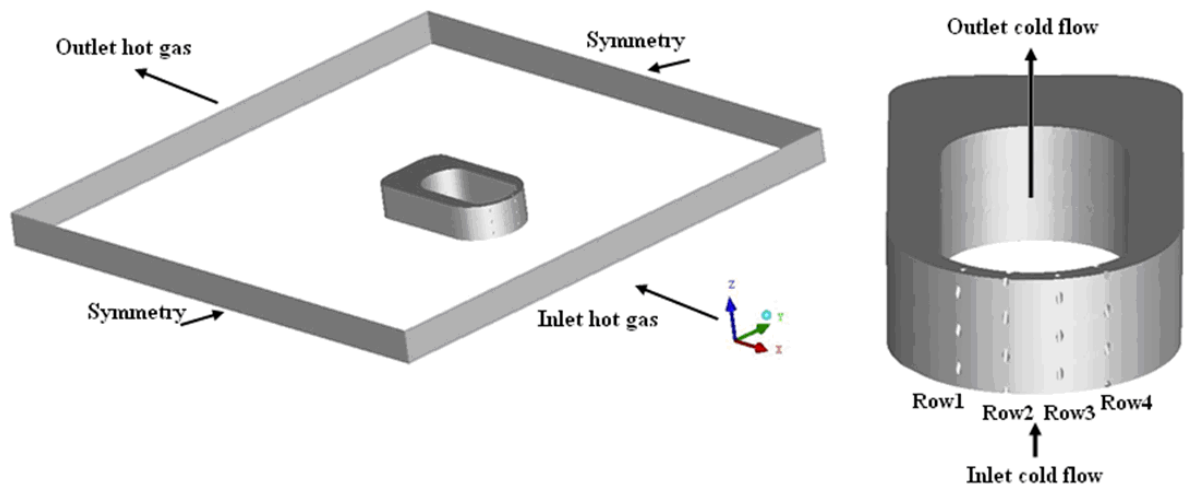

Fig. 3. Computational domain and boundary conditions.

Table 2. Material properties of plexiglas [4].

\begin{tabular}{lc}
\hline \multicolumn{2}{c}{ Plexiglas } \\
\hline Thermal conductivity & $0.19 \mathrm{~W} \cdot \mathrm{m}^{-1} \cdot \mathrm{K}^{-1}$ \\
Density & $1190 \mathrm{~kg} \cdot \mathrm{m}^{-3}$ \\
Molar mass & $1 \mathrm{~kg} \cdot \mathrm{kmole}^{-1}$ \\
Specific heat capacity & $1470 \mathrm{~J} \cdot \mathrm{kg}^{-1} \cdot \mathrm{K}^{-1}$ \\
\hline
\end{tabular}

at $132 \mathrm{~m} . \mathrm{s}^{-1}$ corresponding to a Mach of 0.36 . The coolant fluid is provided from a simple plenum chamber and comes from the bottom. In the experiment tests [4], the solid material which is made of plexiglas only thermal conductivity is provided. As the physical parameters of the blunt body material are not available, two cases are used from the data base of the computational code. The first one has high level of thermal conductivity and the second is classed as low thermal conductivity.

The computational domains as well as the boundary conditions are shown in Figure 3. The distance between the stagnation point of the model and the inlet side and the outlet side were $100 \mathrm{~mm}$ and $200 \mathrm{~mm}$ respectively. The sidewall is about $100 \mathrm{~mm}$ from the stagnation point. Symmetry conditions have been imposed on the sidewall of the computational domain. The mass flow of plenum chamber is calculated by the blowing ratio imposed at the inlet of the coolant flow. The turbulence intensity is set of $5 \%$ and the temperatures of the coolant flow and heat gas was fixed at $30{ }^{\circ} \mathrm{C}$ and $53.5{ }^{\circ} \mathrm{C}$ respectively. Five different average blowing $\operatorname{ratios}(\mathrm{G})$ of $0.4,0.6,09$,
1.2 and 1.4 were investigated in current study. Calculations were conducted using the CFX 12 that solves the RANS equations on unstructured grids. It uses a second order high resolution convection scheme [21] and the SIMPLE pressure-velocity coupling formulated for compressible flow.

In the present work, the shear stress transport (SST) turbulence model [19] is used as a turbulence closure. The SST model works by solving a turbulence/frequencybased model $(k-\omega)$ near the wall and a $k-\varepsilon$ model in the bulk flow, the first grid points are placed at $y+$ less than 2 . This, and in the fully turbulent region is the $k-\varepsilon$ model. This model gives more effectively captures flow separation under an adverse pressure gradient than other eddy viscosity models, and thus more precisely predicts the nearwall turbulence that plays a vital role in the prediction of turbulent heat transfer. This report is also confirmed by other researches as [22].

The formulation of the SST model is described by Vieser [19]:

$$
\begin{aligned}
\frac{\partial(\rho k)}{\partial t}+\frac{\partial\left(\rho U_{j} k\right)}{\partial x_{j}}= & \tilde{P}_{k}-\beta^{*} \rho \omega k+\frac{\partial}{\partial x_{j}}\left(\Gamma_{k} \frac{\partial k}{\partial x_{j}}\right) \\
\frac{\partial(\rho \omega)}{\partial t}+\frac{\partial\left(\rho U_{j} \omega\right)}{\partial x_{j}}= & \frac{\gamma}{\nu_{t}} P_{k}-\beta \rho \omega^{2}+\frac{\partial}{\partial x_{j}}\left(\Gamma_{\omega} \frac{\partial \omega}{\partial x_{j}}\right) \\
& +\left(1-F_{1}\right) 2 \rho \sigma_{\omega 2} \frac{1}{\omega} \frac{\partial k}{\partial x_{j}} \frac{\partial \omega}{\partial x_{j}}
\end{aligned}
$$




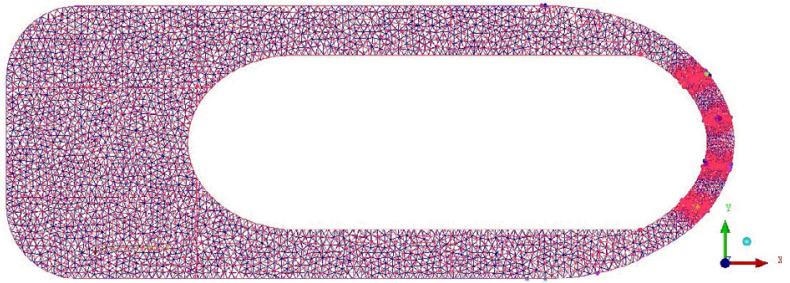

Fig. 4. Computational grid for solid domain (case $G=0.4$ ).

with

$$
\Gamma_{k}=\mu+\frac{\mu_{t}}{\sigma_{k}} \Gamma_{\omega}=\mu+\frac{\mu_{t}}{\sigma_{\omega}} P_{k}=\tau_{i j} \frac{\partial U_{i}}{\partial x_{j}} \tilde{P}_{k}=\min \left(P_{k}, c_{l} \varepsilon\right)
$$

The coefficients, $\varphi$, of the model are functions of $F_{1}: \varphi=$ $F_{1} \varphi_{1}+\left(1-F_{1}\right) \varphi_{2}$, where $\varphi_{1}, \varphi_{2}$ stand for the coefficients of the $k$ - $\omega$ and the $k-\varepsilon$ models respectively:

$$
\begin{aligned}
\sigma_{k 1} & =2.0, \quad \sigma_{\omega 1}=2.0, \quad \gamma_{1}=0.5532, \quad \beta_{1}=0.0750, \\
\beta^{*} & =0.09, \quad c_{l}=10, \quad \kappa=0.41 \quad \sigma_{k 2}=1.0, \\
\sigma_{\omega 2} & =1.168, \quad \gamma_{2}=0.4403, \quad \beta_{2}=0.0828
\end{aligned}
$$

with

$$
\begin{aligned}
F_{1} & =\tanh \left(\arg _{1}^{4}\right) \\
\arg _{1} & =\min \left(\max \left(\frac{\sqrt{k}}{\beta^{*} \omega y} ; \frac{500 \nu}{y^{2} \omega}\right) ; \frac{4 \rho \sigma_{\omega 2} k}{C D_{k \omega} y^{2}}\right) \\
C D_{k \omega} & =\max \left(2 \rho \sigma_{\omega 2} \frac{1}{\omega} \frac{\partial k}{\partial x_{j}} \frac{\partial \omega}{\partial x_{j}} ; 1.0 \mathrm{e}^{-10}\right) \\
F_{2} & =\tanh \left(\arg _{2}^{2}\right), \quad \arg _{2}=\max \left(2 \frac{\sqrt{k}}{\beta^{*} \omega y} ; \frac{500 \nu}{y^{2} \omega}\right) \\
\tau_{i j} & =\mu_{t}\left(\frac{\partial U_{i}}{\partial x_{j}}+\frac{\partial U_{j}}{\partial x_{i}}-\frac{2}{3} \frac{\partial U_{k}}{\partial x_{k}}\right)-\frac{2}{3} \rho k \delta_{i j}
\end{aligned}
$$

The Navier-Stokes and the energy equations are solved on the blunt body by the finite volume method.

The theoretical finite volume method will be not exposed in this section considering that it is of the standard literature [6]. Convergence was attained when the RMS (root-mean-squared) residual values of all flow parameters fell below $10^{-5}$, and the imbalances in both mass and energy in the entire computational domain were each less than $0.001 \%$. To take into account the conduction heat transfer inside the blunt body, the grid generated for both the fluid and the solid domain. Combined transfer conditions have been imposed on the fluid-solid interface. This grid was chosen after several tests considering as well the complex configuration of the studies cases. An overview of the grid is shown in Figures 4 and 5. It noted that other denser grids were used for the other cases at increasing of Reynolds number $(R e=1.09 \mathrm{E}+05, R e=1.52 \mathrm{E}+05)$ especially near the wall.

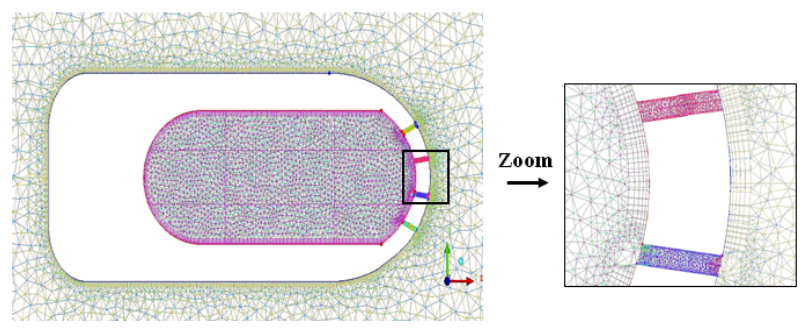

Fig. 5. Computational grid for fluid domain (case: $G=0.4$ ).

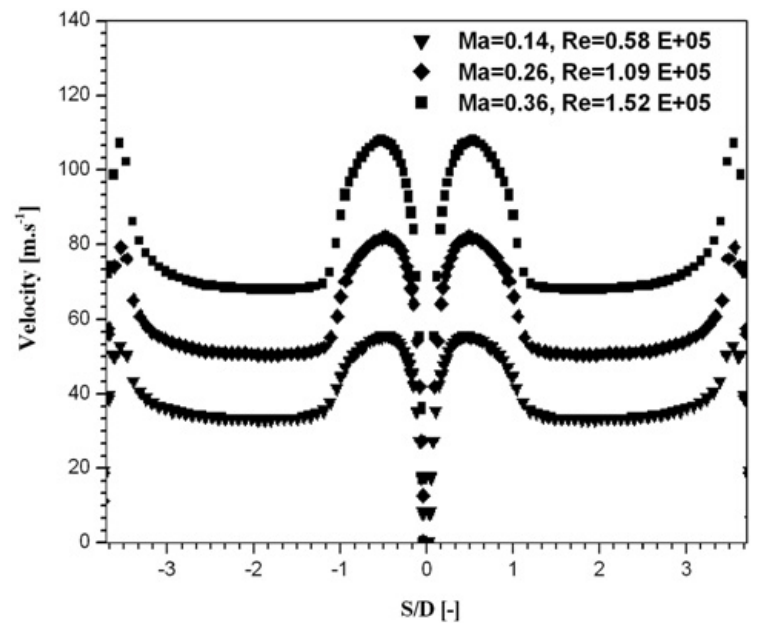

Fig. 6. Velocity distribution around the blunt without injection holes.

\section{Results and discussion}

This study is carried out in three distinct steps. An influence of the blowing ratio is presented in the first step. Numerical results obtained for blowing ratios $(G=0.4$, $0.6,0.9,1.2$ and 1.4) are compared with experimental results of Falcoz [5]. The second step involves the Mach number study for cooled leading edge. Thermal conductivity effect is discussed in the third step.

The result of overall cooling effectiveness will be compared with experimental measurement by Falcoz [5]. Before conduction heat transfer and film cooling results, it was necessary to characterize the aerodynamic flow field in the linear test facility, and to check the alignment of the model within the computational domain. Three different mainstream flow conditions were investigated yielding inlet Reynolds numbers of $0.58 \times 10^{5}, 1.09 \times 10^{5}$ and $1.52 \times 10^{5}$ corresponding to inlet Mach numbers of $0.14,0.26$ and 0.36 respectively. The velocity distribution around the blunt body without injections holes are shown in Figure 6. Here, the surface coordinate, $S$, is used, which has its origin at the position of the stagnation line of the profile. For all investigated conditions, the flow velocities on both sides were superimposed. Excellent symmetry was found for all Reynolds numbers.

In Figure 7, the spanwise averaged heat transfer test sections without film cooling holes are plotted against the non-dimensional surface $S / D$ for three mainstream flow conditions. For all Reynolds numbers, the curves exhibit 


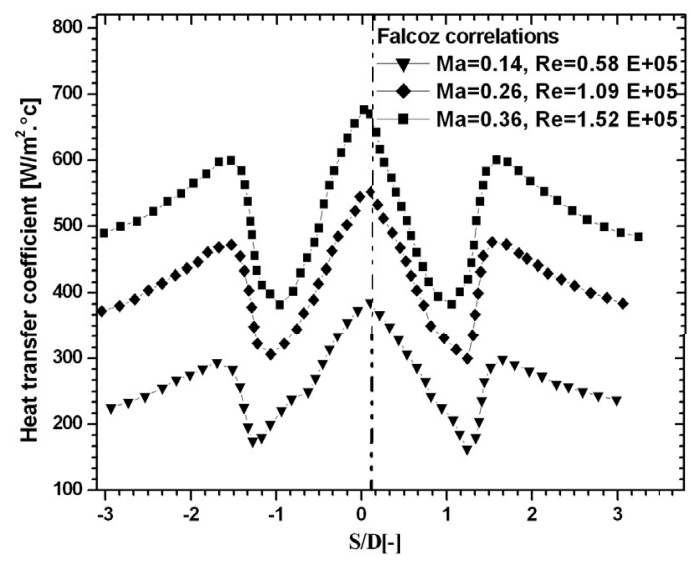

(a)

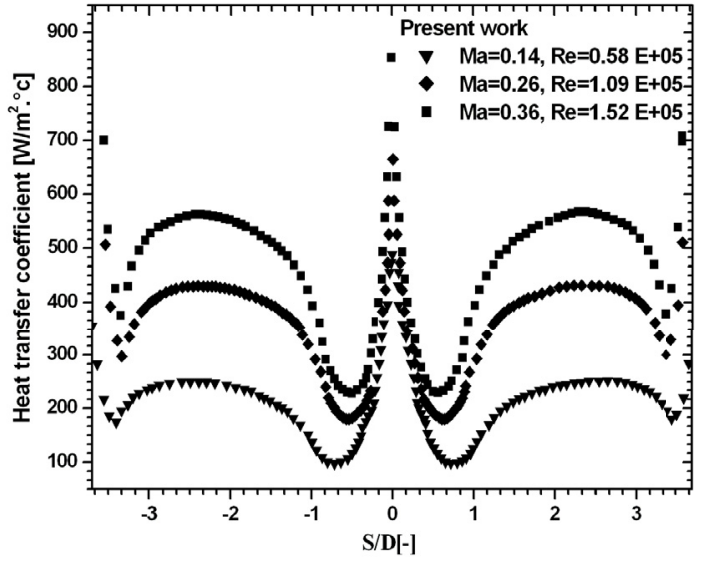

(b)

Fig. 7. Heat transfer coefficient around the bunt body without injection holes. (a) Falcoz correlations, (b) numerical work.

similar trends: the heat transfer coefficient reaches its highest value at the stagnation point where the laminar boundary layer starts growing, decreases abruptly in the strongly accelerated zone until the onset of the boundary layer transition, then rises dramatically to a second peak value located at $S / D=2.5$ corresponding to completion of the transition, and finally, fall off in the fully turbulent boundary layer region. For all investigation flow conditions, an excellent symmetry around the stagnation point $(S / D=0)$ can be observed. In addition, the high heat transfer near the stagnation point is clearly visible; it can also be seen that the transition point moves upstream with increasing Reynolds numbers. The curves obtained of velocities and heat transfer coefficients are in agreement with the correlations of Falcoz [5].

\subsection{Blowing ratio effect}

This first part of the study serves as validation of the calculation and investigation of effect of blowing ratio. Figure 8 shows temperatures distribution on leading edge of a blunt body models at $M=0.36, R e=$ $1.52 \times 10^{5}$ (plexiglas) with varied blowing rates for both right side $(+S / D)$ and left side $(-S / D)$ respectively. In addition to the good symmetry on the both sides, the positions of the coolant flow injection are characterized by two negatives peaks, which also marked a transition in thermal boundary layer. Beyond the first row the temperature increase continuously pronounced the attenuation of film cooling mechanism. This finding is confirmed by Figure 8 with the detailed evolution curves of the film cooling especially passing by the central rows (rows 2 and 3 at $-7.5^{\circ}$ and $+7.5^{\circ}$ ). It can be seen that the best coverage of the blade surface is provided for $G=0.6$ lateral injection. These observations are thus analyzed and detailed by Bohn [7].

Figures 10 and 11 show temperatures distribution and film cooling effectiveness contours on the blade surface at $M=0.36, R e=1.52 \times 10^{5}$ (plexiglas) with varied blowing rates respectively. Leading to good film coverage can be observed behind rows at low to moderate blowing ratios, and disappear for $G=1.4$. This phenomenon has been widely described in the literature and is known as jet "lift off", the effectiveness for high blowing rates suffers from excessive penetration of the injected air into the main stream. We note that these observations are also confirmed by previous investigations [1-3].

Figure 12 shows a comparison of the overall cooling efficiency computed with Falcoz correlations [4]. The comparison is acceptable and shows a marked global improvement proportional to the blowing ratio.

\subsection{Mach number effect}

To study the influence of Mach number on the thermodynamic structure of the flow, a simulation at Mach = 0.36 and low Mach number (0.14) was conducted.

Figures 13 and 14 show the efficiency of film cooling on the blunt body. The values corresponding to the highest Mach are the most important.

Figure 15 represents the overall efficiency as a function of the blowing ratio and Mach number. The shape of the curves confirms the improved cooling in proportion to the blowing ratio and also shows that the most favorable conditions are those related to the Mach number the greater.

\subsection{Thermal conductivity effect}

The material of the blunt body used in the previous study is in plexiglas. The low thermal conductivity of this material has a great influence on the results, for both experimental and numerical results. The walls in this case are almost adiabatic and physically, the film cooling is dominant. In actual use conditions, the material of gas 


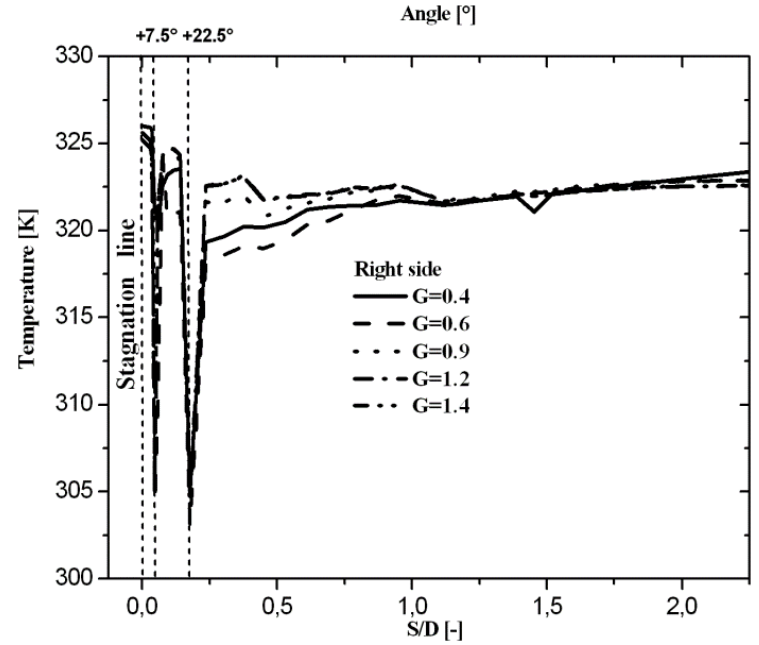

(a)

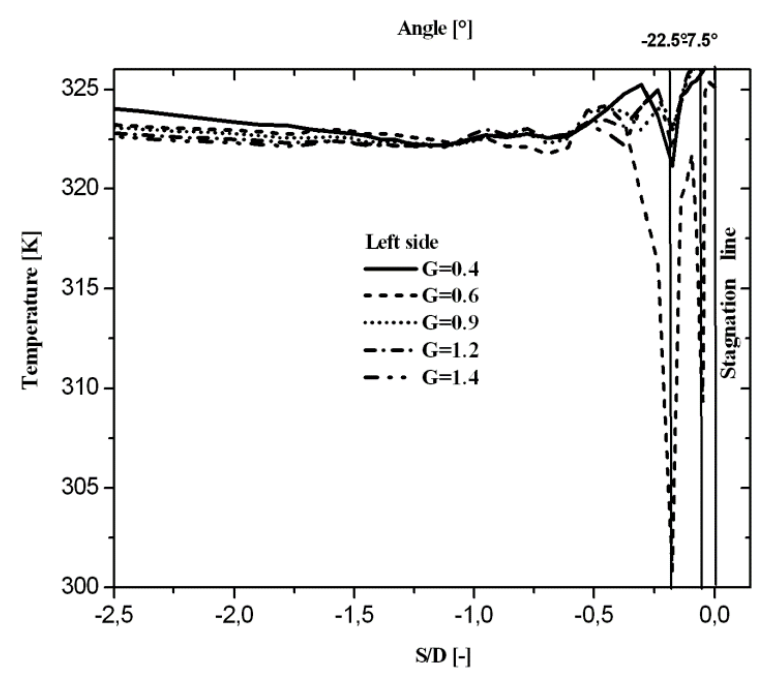

(b)

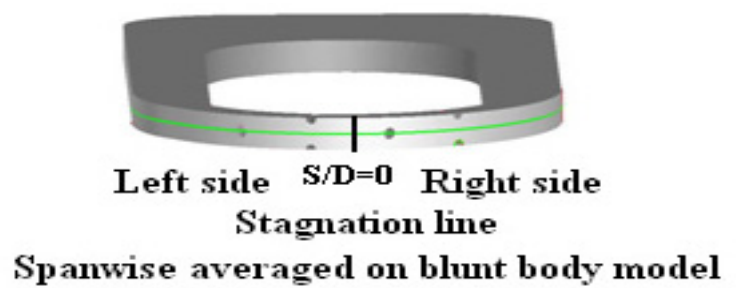

Fig. 8. Lateral temperature distribution on left side of blunt body at $M=0.36, R e=1.52 \times 10^{5}$ (plexiglas) with varied blowing rates, (a) right side, (b) left side.

turbine blades is a metal with high thermal conductivity. The internal cooling in the plenum side and inside the holes becomes more important in the global cooling. In order to illustrate the effect of the thermal conductivity of the blade in the cooling process, the same previous study was conducted with a material of high thermal conductivity and will be called real condition. The Mach number

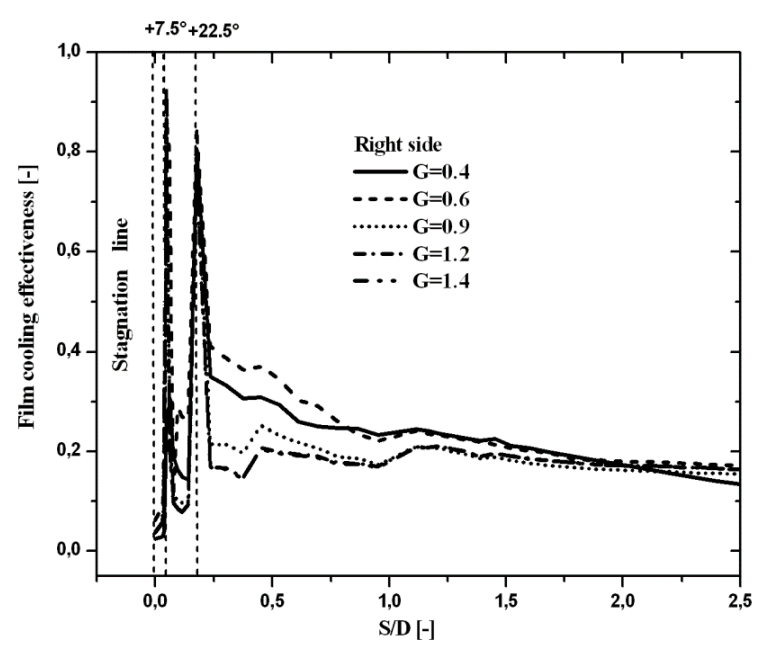

(a)

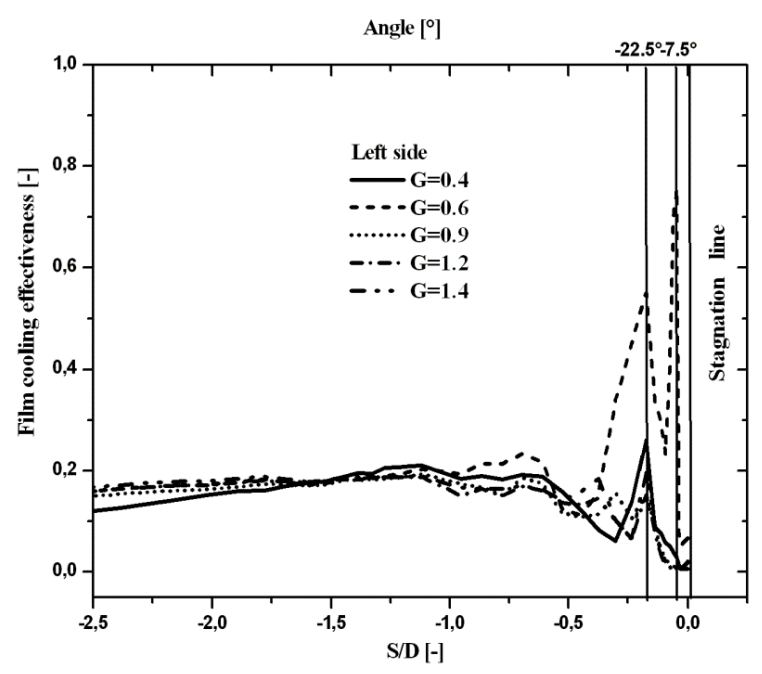

(b)

Fig. 9. Film cooling effectiveness on leading edge of a blunt body model at $M=0.36, R e=1.52 \times 10^{5}$ (plexiglas) with varied blowing rates (a) right side, (b) left side.

Table 3. Material properties of steel.

\begin{tabular}{lc}
\hline \multicolumn{2}{c}{ Steel } \\
\hline Thermal conductivity & $20 \mathrm{~W} \cdot\left(\mathrm{m}^{-1} \cdot \mathrm{K}^{-1}\right)$ \\
Density & $7854 \mathrm{~kg} \cdot \mathrm{m}^{-3}$ \\
Molar mass & $55.85 \mathrm{~kg} \cdot \mathrm{kmole}^{-1}$ \\
Specific heat capacity & $434 \mathrm{~J} .\left(\mathrm{kg}^{-1} \cdot \mathrm{K}^{-1}\right)$ \\
\hline
\end{tabular}

is maintained at 0.36 while the three injection rates were tested. Table 3 shows the materials properties of steel.

Figure 16 shows the overall cooling effectiveness of the two materials versus the blowing ratio. It should be noted that the case of steel shows a heat exchange level higher than that recorded for the case of plexiglas. This results in greater overall efficiency for the case of plexiglas. 

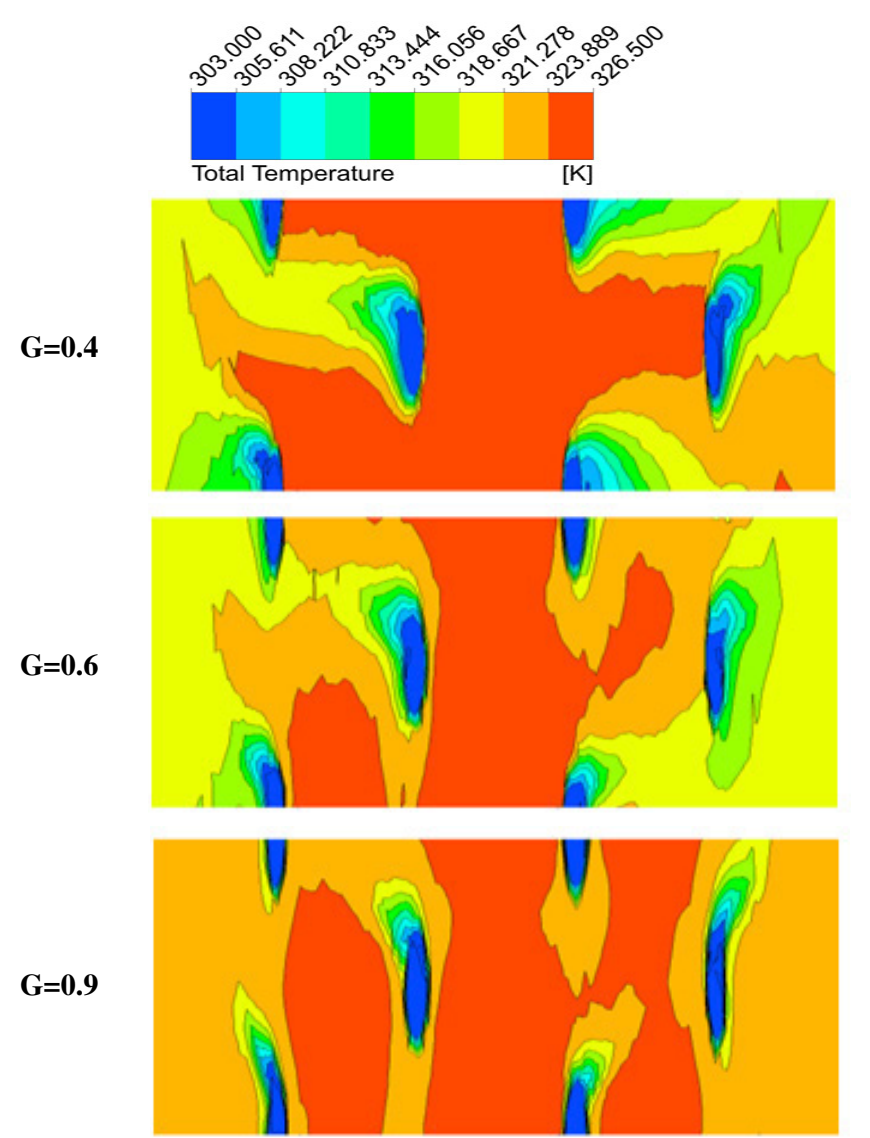

$\mathbf{G}=\mathbf{1 . 2}$

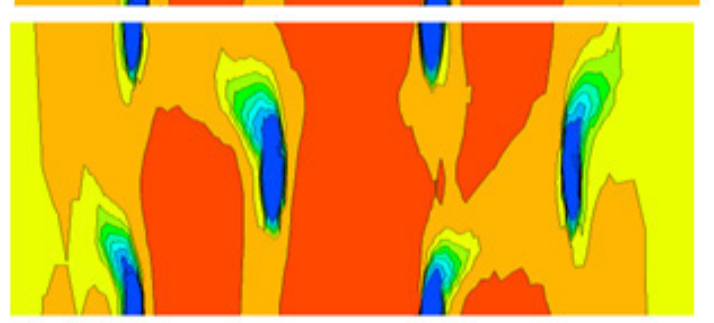

$\mathbf{G}=\mathbf{1 . 4}$

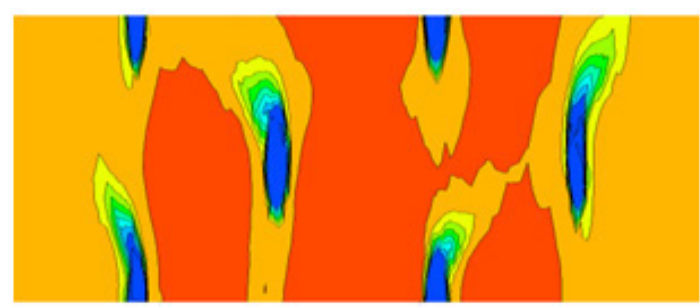

Fig. 10. Temperatures distribution contours on leading edge of a blunt body model at $M=0.36, R e=1.52 \times 10^{5}$ (plexiglas) with varied blowing rates.

\section{Conclusion}

The coupled internal and external cooling of the leading edge for a blunt body shape was performed using three-dimensional Reynolds averaged Navier Stokes analysis with the SST $k-\omega$ model. The results of the numerical simulation can be summarized as follows:

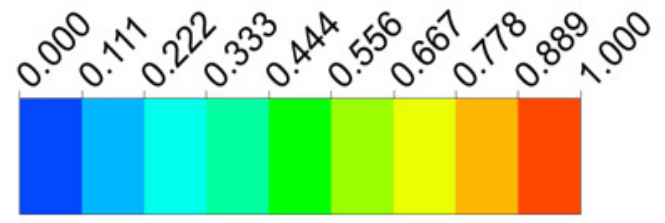

$\eta$

$\mathbf{G}=\mathbf{0 . 4}$

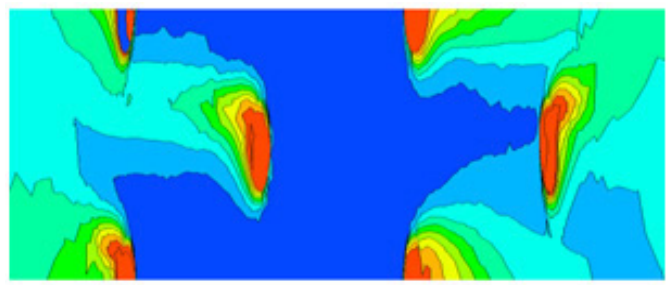

$\mathbf{G}=\mathbf{0 . 6}$

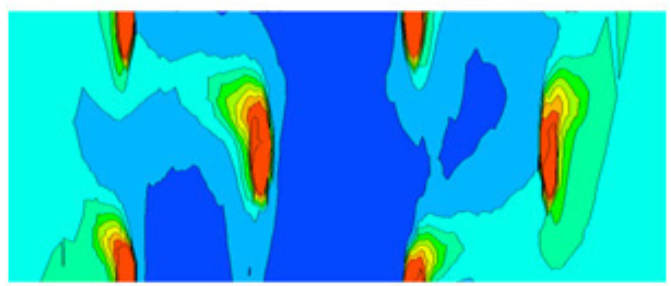

$\mathbf{G}=\mathbf{0 . 9}$

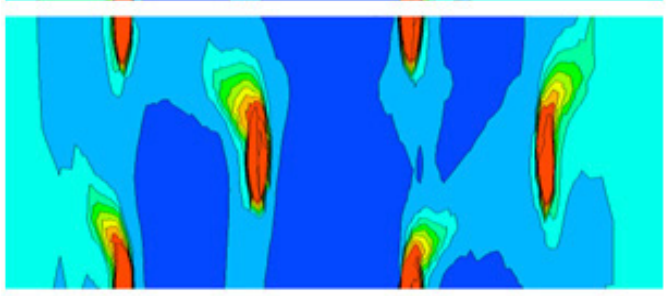

$\mathrm{G}=1.2$

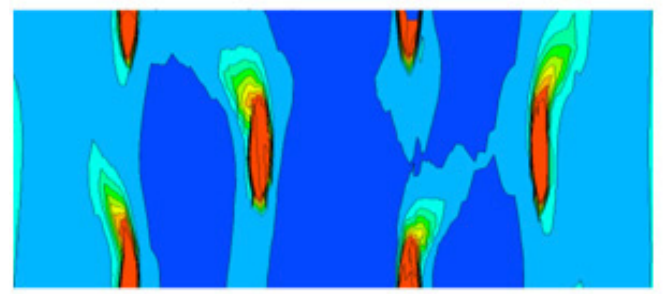

$\mathbf{G}=\mathbf{1 . 4}$

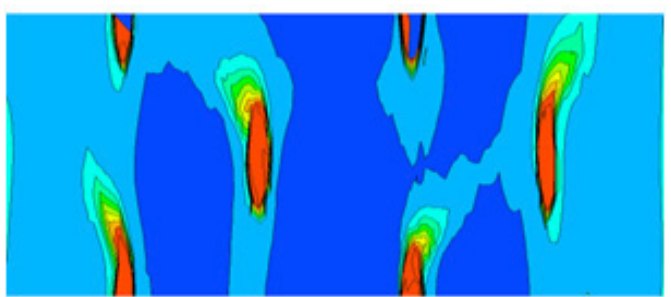

Fig. 11. Film cooling effectiveness contours on leading edge of a blunt body model at $M=0.36, R e=1.52 \times 10^{5}$ (plexiglas) with varied blowing rates.

- The aerodynamic flow confirmed a best threedimensional flow field around the stagnation line.

- The heat transfer coefficient for various flow conditions shows excellent symmetry around the blunt body. At the elevated Mach numbers and Reynolds number the values of the heat transfer coefficient increase.

- For the case of plexiglas, the findings are similar to those found previously in studies on film cooling as isolated processes. Namely, the cooling efficiency increases 


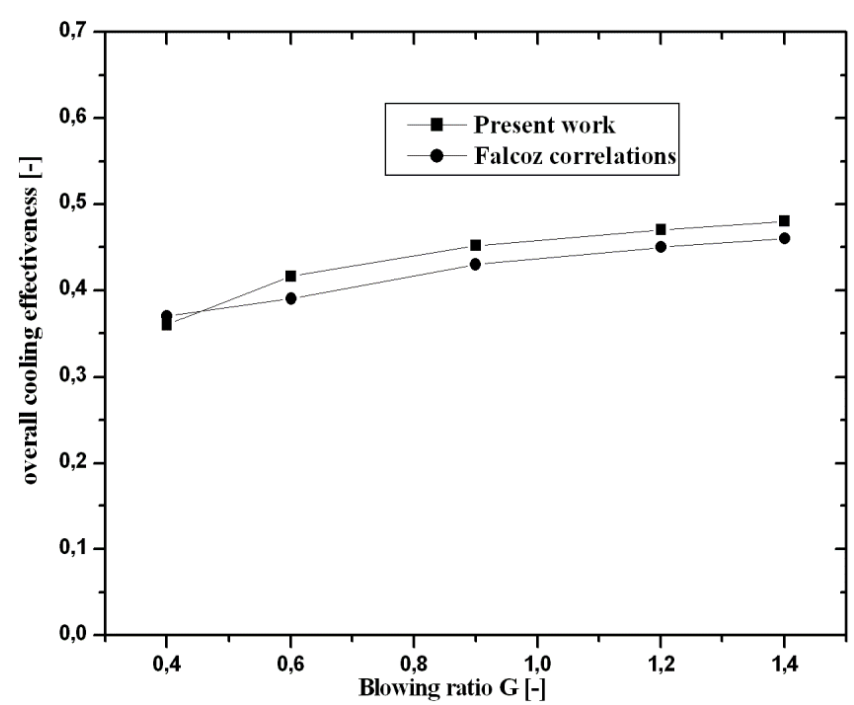

Fig. 12. Overall cooling effectiveness on blunt body model.

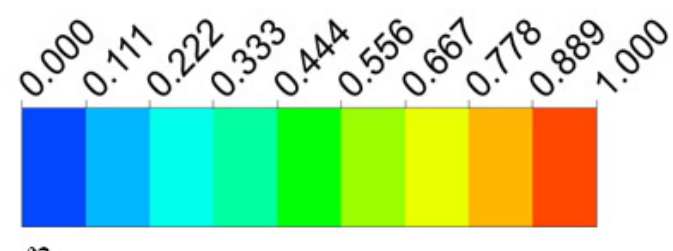

$\eta$

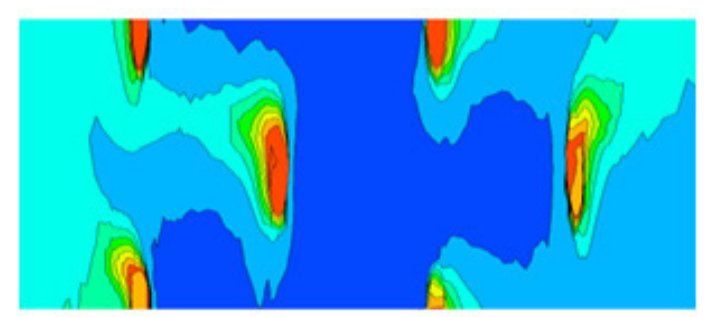

Fig. 13. Film cooling effectiveness contours on leading edge of a blunt body model (plexiglas $M=0.14, G=0.6$ ).
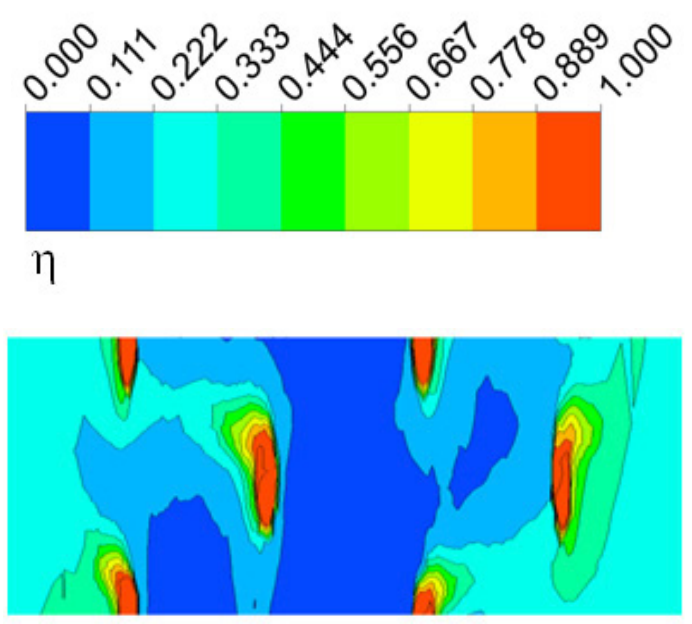

Fig. 14. Film cooling effectiveness contours on leading edge of a blunt body model (plexiglas $M=0.36, G=0.6$ ).

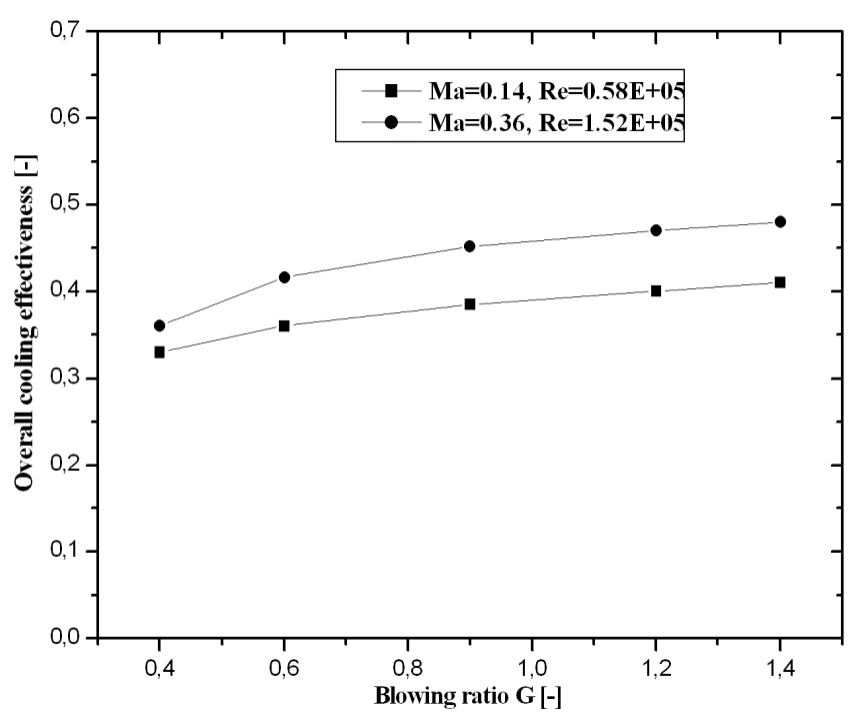

Fig. 15. Overall cooling effectiveness with varied Mach numbers.

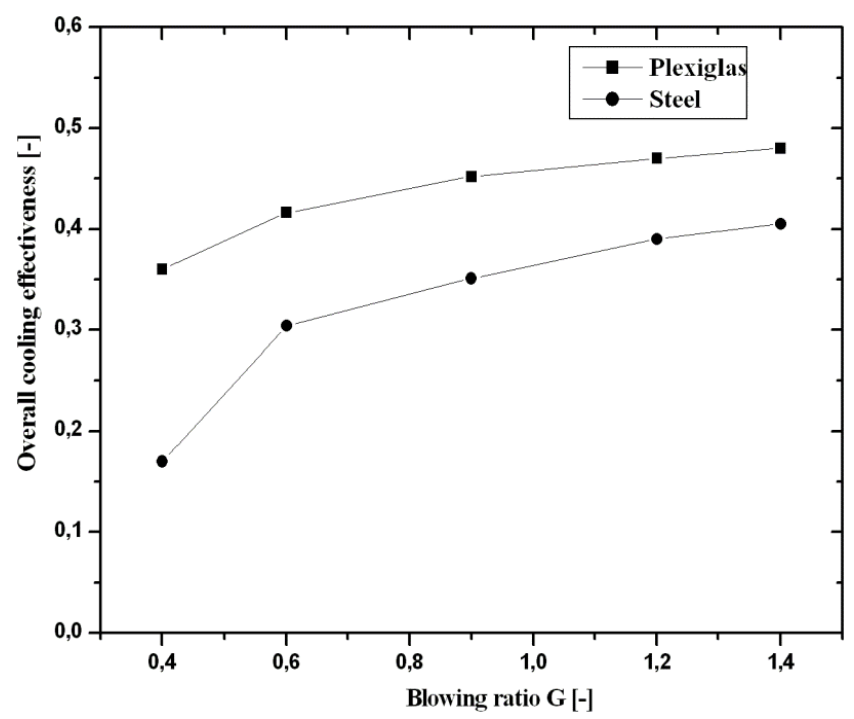

Fig. 16. Overall cooling effectiveness for different materials.

with the increase of the injection rate. An optimum value marks the limit after which the increase of the injection rate results in a decrease in the efficiency of the film cooling. For the case in this study, the value of $G$ is about 0.6 .

- On the other hand, increasing the Mach number improves heat transfer and thereby progressively affects the efficiency of cooling.

- The transition to a material with high thermal conductivity shows the importance of heat transfer in the feeding box inside the injection holes. Therefore the influence of the injection rate on the overall efficiency becomes less important compared to the case in plexiglas. This is a result about the influence of the injection rate on the overall efficiency, loss of its importance compared to the case of plexiglas. 


\section{References}

[1] W.D. York, J.H. Leylek, Leading edge film-cooling physics: Part I - adiabatic effectiveness, 2002, ASME Paper GT2002-30166

[2] A. Azzi, B.A. Jubran, Influence of leading edge lateral injection angles on the film cooling effectiveness of a gas turbine blade, Heat and Mass Transfer 40 (2004) 501-508

[3] W.D. York, J.H. Leylek, Leading edge film-cooling physics: Part II - heat transfer coefficient 2002, ASME Paper GT2002-30167

[4] C. Falcoz, A Comparative Study of Showerhead Cooling Performance, Ph.D. Thesis N2735, Swiss Federal Institute of Technology-Lausanne (EPFL), 2003

[5] C. Falcoz, B. Weigand, P. Ott, Experimental investigations on showerhead cooling on a blunt body, Int. J. Heat Mass Transfer 49 (2006) 1287-1298

[6] C. Falcoz, B. Weigand, P. Ott, A comparative study on showerhead cooling performance, Int. J. Heat Mass Transfer 49 (2006) 127-1286

[7] D. Bohn, J. Ren, K. Kusterer, Conjugate heat transfer analysis for film cooling configurations with different hole geometries, 2003, ASME Paper GT2003-38369

[8] Youn J. Kim , S.-M. Kim, Influence of shaped injection holes on turbine blade leading edge film cooling, Int. J. Heat Mass Transfer 47 (2004) 245-256

[9] A.O. Demuren, W. Rodi, B. Schonung, Systematic study of film cooling with a three-dimensional calculation procedure, Trans. ASME, J. Turbomach. 108 (1986) 124-130

[10] Z. Gao, J. Han, Influence of Film-Hole Shape and Angle on Showerhead Film Cooling Using PSP Technique, Trans. ASME, J. Heat Transfer 131 (2009) 061701061701-11

[11] K.D. Lee, K.Y. Kim, Performance Evaluation of a Novel Film-Cooling Hole, Trans. ASME, J. Heat Transfer 134 (2012) 101702-101702-7

[12] T. Elnady, I. Hassan, L. Kadem, T. Lucas, Cooling effectiveness of shaped film holes for leading edge, Exp. Thermal Fluid Sci. 44 (2013) 649-661
[13] Y.J. Kim, S.M. Kim, Influence of shaped injection holes on turbine blade leading edge film cooling, Int. J. Heat Mass Transfer 47 (2004) 649-661

[14] S.P Harasgama, Aero-thermal Aspects of Gas Turbine Flow-Turbine blading internal cooling, VKI Lecture Series 1995-05, Heat transfer and cooling in gas turbines, 1995

[15] D. Lakehal, G.S. Theodoridis, W. Rodi, Three dimensional flow and heat transfer calculations of film cooling at the leading edge of a symmetrical turbine blade model, Int. J. Heat Fluid Flow 22 (2001) 113-122

[16] P.M. Ligrani, A.E. Ramsey, Film Cooling from SpanwiseOriented Holes in Two Staggered Rows, Trans. ASME, J. Turbomach. 119 (1997a) 562-567

[17] P.M. Ligrani, A.E. Ramsey, Film Cooling from a Single Row of Holes Oriented in Spanwise/Normal Planes, Trans. ASME, J. Turbomach. 119 (1997b) 770-776

[18] B.Y. Maiteh, B.A. Jubran, Influence of mainstream flow history on film cooling and heat transfer from two rows of simple and compound angle holes in combination, Int. J. Heat Fluid Flow 20 (1999) 158-165

[19] W.T. Vieser, F. Menter, Heat Transfer Predictions using advanced Two-Equation Turbulence Models, CFXVAL10/0602, AEA Technology, CFX Documentation, 2001

[20] Y. Yao, J. Zhang, Y. Yang, Numerical study on film cooling mechanism and characteristics of cylindrical holes with branched jet injections, Propulsion and Power Research 2 (2013) 30-37

[21] A. Kurganov, E. Tadmor, New High-Resolution Central Schemes for Nonlinear conservation Laws and ConvectioDiffusion Equation, J. Comput. Phys., 160 (2000) 241282

[22] J.E. Bardina, P.G. Huang, T. Coakley, Turbulence Modeling Validation, 28th Fluid Dynamics Conference, AIAA Paper No. 1997-2121, 1997 